\title{
De madres y de expertos: la psicología de posguerra y el disciplinamiento de los cuidados maternos
}

\section{Of mothers and experts: the psychology of post war period and the disciplining of maternal care}

\author{
Claudia Calquín Donoso ${ }^{1}$ \\ Universidad de Barcelona, España
}

(Rec: octubre 2012 - Acep: mayo 2013)

\begin{abstract}
Resumen
El artículo reflexiona acerca de la construcción discursiva de los cuidados maternos en la psicología. Se discute la emergencia de estos saberes y su relación con las transformaciones políticas y económicas ocurridas durante el periodo de posguerra y el inicio de la guerra fría. Desde una perspectiva foucaultiana, la hipótesis general que guía la reflexión desde una perspectiva foucaultiana, señala que los cuidados son menos prácticas individuales y espontáneas de las madres, que efectos de relaciones de poder/saber históricamente situadas y una práctica social a través de la cual, la psicología se erigió como ciencia y dispositivo de la normalidad y la subjetividad.

Palabras claves: Michel Foucault, cuidados maternos, feminismo, disciplina, Historia de la Psicología
\end{abstract}

\begin{abstract}
The article reflects on the discursive construction of maternal care in Psychology. We discuss the emergence of this knowledge and its connections to the political and economic transformations occurred during the postwar period and the beginning of the Cold War. From a Foucauldian perspective, the general hypothesis guiding this reflection states that motherly care practices, rather than having an individual and spontaneous character, represent a product of power relationships and knowledge relationships both historically situated and a social practice through which, Psychology emerged as science and device of normality and subjectivity.
\end{abstract}

Keys words: Michel Foucault, maternal care, feminism, discipline, History of Psychology

\footnotetext{
Correspondencia a: Mare de deu de lorda 48, 2ª , CP 8013, Barcelona, España. E-mail: ccalquindonoso@gmail.com.
} 


\section{Introducción}

“...será preciso demostrar un día como las relaciones intrafamiliares, esencialmente en la célula padres-hijos, se han "disciplinado", absorbiendo desde la época clásica esquemas externos, escolares, militares y después médicos, psiquiátricos, psicológicos, que han hecho de la familia el lugar de emergencia privilegiada para la cuestión disciplinaria de

lo normal y anormal..." (Foucault, 1974, p. 219)

Que para los profesionales de las ciencias sociales, la familia sea un lugar privilegiado de producción y circulación de la normas, es un asunto más o menos aceptado, pero que lo sea de la disciplina es un enunciado relativo, en tanto la disciplina para muchos de ellos constituye apenas una forma de crianza en desuso.

Campañas como la "democratización de las familias" impulsada por UNICEF, así como la vieja clasificación elaborada por Ron Lippit y Robert White en 1939, constituyen ejemplos de enunciados que de alguna u otra forma sitúan a la disciplina y su ejercicio, como una cuestión "relacional" más o menos ligada a la voluntad y capacidad individual de los sujetos para gestionar las relaciones afectivas y los vínculos familiares.

Esta psicologización de la disciplina, que subsume su naturaleza a un estilo de crianza y a una forma de relación, disimula que ésta constituye una práctica compleja de producción de normalidad, es decir, una práctica vinculada a la propagación de técnicas de control riguroso de las operaciones del cuerpo y la subjetividad, con el objetivo de garantizar una sujeción continua a un sistema de normas. Se trata de una economía del poder propia del orden moderno, en la cual el control y la vigilancia permanente se erigen como modalidad de gobierno y de relación entre los sujetos, y entre los sujetos, los saberes y las instituciones (Foucault, 1974).

Desde el punto de vista de los saberes "disciplinarios" (otras de las acepciones que la disciplina evoca), en los últimos años se ha desarrollado un importante campo de investigación histórica sobre las ciencias $p s i$ y la medicina, en el que se insiste en la idea de vincular la historia de la producción de conocimiento de estas "disciplinas" con la historia del disciplinamiento de las familias (Foucault, 1974; Rose, 1990; 1998; Chambon, Irving \& Epstein, 2001; Castell, 1984; 2003), y también, aunque de modo marginal, con el de las mujeres (Haraway, 1995; Donzelot, 1998; Palacio, 2003; Enhrenreich \& English, 1990; Ruiz y Palacio, 1999).
En este sentido, han sido las preocupaciones por el desarrollo del estado de bienestar durante la segunda posguerra mundial, las que han enfatizado la dimensión epistemológica de las "disciplinas" y sus efectos en la construcción de la subjetividad moderna.

Con esto emerge otra dimensión de la relación entre disciplina y familia, aquella que interroga a las "disciplinas" como ciencias, es decir, prácticas occidentales de producción de saber, especialmente aquellas que han hecho de las relaciones familiares su foco de atención. Se intenta en esta segunda dimensión, identificar a la familia y más precisamente a la disciplina familiar, en lo que Donzelot (1998) llama el "complejo tutelar", es decir, en una red de conocimientos e intervenciones sobre lo humano que se constituyen como parte de un sistema civilizador del cuerpo social ligado al Estado.

Si tomamos la disciplina que se relaciona con la historia de las prácticas de cuidado materno, es decir, con la construcción cultural de los repertorios y significados de las prácticas de sostenimiento de la vida (Carrasco, 2001), el problema que me interesa analizar en este trabajo, es la articulación de estos cuidados en el discurso psicológico. De este modo, planteo como hipótesis que la discursividad psicológica sobre los cuidados parentales expresa, no tanto las formas en que el cuidado se organiza y se ejerce en la sociedad, sino la función normalizadora de esta "disciplina".

En un mismo instante esta función expresaría la construcción histórica de los cuerpos, sus usos y relaciones en lo que Foucault llama, "cuerpos dóciles" y así mismo, la formulación de modelos de relaciones y vínculos familiares de acuerdo a un modelo de normalidad y salud que las mismas tecnologías $p s i$ producen (Rose, 1998).

Por lo tanto, se trata de comprender cómo las disciplinas sociales al plantearse como objetivo conducir a las familias a la normalidad, la salud o el desarrollo social, instalan con ello mecanismos y funciones de disciplinamiento, control y vigilancia, que se confunden en la misma relación asimétrica entre instituciones/ profesionales y familias. Así en el momento en que las familias, especialmente las populares, son objeto de intervención social, comienzan a circular en un campo de saber/poder, que más que delimitar o restringir sus actuaciones (que sería la disciplina bloqueo en palabras de Macharay (en Balbier,1990)), las produce, de acuerdo a modelos y objetivos disciplinarios de conducta y de relaciones.

A través de un ejemplo histórico se argumentará que en las sociedades occidentales, los cuidados maternos (sus repertorios, significados y objetivos) son menos 
prácticas individuales y espontáneas de las madres, que efectos de relaciones de poder/saber históricamente situadas y una práctica social a través de la cual la psicología se erigió como ciencia y dispositivo de la normalidad y la subjetividad.

\section{El carácter polisémico de la disciplina}

Uno de los autores a quien debemos la conceptualización sobre las disciplinas es Michel Foucault. En Vigilar y Castigar (Foucault, 1974) define las disciplinas como "esos métodos que permiten el control minucioso de las operaciones del cuerpo, que garantizan la sujeción de las fuerzas y les impone una relación de docilidad-utilidad" (p. 141).

A pesar de lo concreto de la definición, es claro que en los trabajos de Foucault (1974, 2006, 2010) el concepto se desplaza por múltiples sentidos, usos y niveles analíticos, expresando la naturaleza polisémica y equívoca de la disciplinas como modalidad de control, de relación, como tecnología del cuerpo y del yo, como saber y como tecnología de gobierno. Esta última perspectiva afirma que la extensión, consolidación y penetración en el cuerpo social de las técnicas y saberes disciplinarios, lograron conformar una "sociedad disciplinaria", cuyos alcances son un tema de más amplias consecuencias que trasciende los objetivos de este trabajo.

Esta visión polisémica expresa, como bien lo discute Caruso (2003), el carácter múltiple de las consecuencias en los espacios sociales de la difusión de las disciplinas. En esto Foucault es enfático, al señalar que las disciplinas "no pueden ser identificadas ni a una institución ni a un aparato" (Foucault, 1974, p. 219). Al no estar territorializadas, tienen la capacidad de evocar múltiples sentidos, he ahí su potencia para generar amplios efectos en todos los niveles de la sociedad y que puedan ser confundidas con la sociedad misma.

En ese sentido constituye un error común identificar y reducir las "disciplinas" al dispositivo panóptico y por consiguiente, a las instituciones cerradas o semicerradas. Este error por un lado, desvirtúa el hecho que "el panoptismo no es una mecánica regional y limitada a instituciones, (...) es sin duda una fórmula política general que caracteriza un tipo de gobierno" (Foucaul, 2010, p. 89). Por otro lado, lo que propone Foucault es un modo abstracto de comprender la relación entre los espacios, las formas arquitectónicas y la formación de una relación social.

Siguiendo a Caruso (2003), la potencia heurística del concepto, pasa por pensar las disciplinas más como estrategias que como modelo de sociedad a las que podemos añadirlos atributos de localizadas, regionales y situadas (Haraway, 1995) que se inscriben en determinadas prácticas sociales, como son los cuidados maternos.

Para ello, una primera proposición es pensar que la relación entre disciplina y familias no muestra, en palabras de Foucault, una forma negativa ya sea de exclusión, de prohibición o represión. Se trata de pensar las disciplinas en el seno de la transformaciones históricas de la industrialización moderna y la racionalidad gubernamental liberal (Foucault, 2010; 2006), que consiste, en términos amplios, en el modelamiento y encausamiento de la subjetividad bajo lo que Foucault denomina una "cuadrícula disciplinaria" (Foucault, 1974; 2006), es decir, una distribución jerárquica y funcional de la multiplicidad.

Desde esta perspectiva hablamos del despliegue de una tecnología de gobierno: la norma, que si bien se ocupa de los problemas antiguos -ordenar la muchedumbre y sujetarlas al poder-, se concreta en una doble operación: segmentar/ componer y aumentar/disminuir las fuerzas del cuerpo.

El primer juego de operaciones trata sobre un trabajo de análisis: descomponer el cuerpo en partes, los actos en gestos y posturas, los colectivos en individuos; y por otro lado, un trabajo de conjunción y composición a partir de un principio económico, Se trata de seleccionar las partes adecuadas para producir cuerpos útiles, actos eficaces, y colectivos bien organizados.

El segundo juego de operaciones consiste en aumentar las fuerzas del cuerpo (en términos económicos de utilidad) y disminuir esas mismas fuerzas (en términos políticos de obediencia). La disciplina, en ese sentido, disocia el poder del cuerpo: "de una parte, hace de este poder una "aptitud", una "capacidad" que trata de aumentar, y cambia por otra parte la energía, la potencia que de ello podría resultar, y la convierte en una relación de sujeción estricta" (Foucault, 1974, p. 135).

Con la disciplina, el control social se desliza de la descomposición del cuerpo/supliciado a su recomposición como cuerpo normativizado. Esto sucede a través de lo que Chambon (en Chambon et al, 2001) llama "prácticas normalizadoras", es decir prácticas que dividen, que producen individuos (en tanto unidad minina de división) y cuyos efectos de poder más evidentes es la distribución de estos en un arquitectura social andamiada sobre polaridades y categorías discretas que no admiten confusión: lo bueno/lo malo, normal/anormal, salud/enfermedad, interior/exterior, uno mismo y lo otro, etc. 
Con ello la disciplina en palabras de Macherey (1990) viene a representar un conjunto de prácticas de la norma ante la cual, el sujeto se constituye como ser pensante (sujeto de saber) y como ser actuante (sujeto de poder). Se trata desde esta perspectiva de abordar la disciplina como "productora" de normalidad.

Una segunda proposición expresa la relación entre familia y saberes disciplinarios. En El orden del discurso (2011) Foucault desarrolla la cuestión de las disciplinas desde lo que llama los principios de control y delimitación del discurso. Estos principios responden a la hipótesis de que "en toda sociedad la producción del discurso está a la vez controlada, seleccionada y redistribuida por cierto número de proposiciones que tienen por función conjurar sus poderes y peligros, dominar el acontecimiento aleatorio y esquivar su pesada y temible materialidad" (Focault, 2011, p. 14).

A diferencia de los procedimientos de control que se ejercen desde el exterior (como los sistemas de exclusión relacionados a la prohibición y la separación) las disciplinas obedecen a lo que Foucault llama procedimientos internos, es decir, que dependen de los discursos mismos y que tienen por fin dominar el acontecimiento y el azar (Foucault, 2011).

Desde esta perspectiva, las disciplinas se definen por un ámbito de objetos, un conjunto de métodos, un corpus de proposiciones consideradas verdaderas, un juego de reglas y de definiciones, de técnicas y de instrumentos, configurando "una especie de sistema anónimo a disposición de quien quiera o quien pueda servirse de él" (Foucault, 2011, p. 33). Asimismo, las disciplinas deben su posibilidad de existencia en el hecho de formular, de modo indefinido, nuevas proposiciones y enunciados, que la misma disciplina (es decir, en el interior de sus propios límites) define como verdaderos o falsos.

Lo que se problematiza con esto, es cómo las disciplinas construyen su propio sistema de inteligibilidad, esto es, sus propios soportes materiales y estrategias de producción, validación y difusión de la verdad, poniendo en juego el sistema mismo de enunciabilidad es decir, la posibilidad de que un enunciado se sitúe o no "en la verdad" (Foucault, 2011, p. 36).

Los efectos de saber del despliegue de las disciplinas del campo psi y que en los últimos años han sido particularmente intensificados, es el nacimiento de un saber experto sobre la subjetividad, por el cual se propagó todo un conjunto de profesionales, cada uno afirmando su virtuosismo respecto al yo, en clasificar y medir la psiquis, en predecir sus vicisitudes, en diagnosticar las causas de sus problemas y prescribir remedios (Rose, 1990).
Si pensamos que en las sociedades neoliberales democráticas, el rol de estado y de sus aparatos, es constantemente cercado, dominado y reducido a su función reguladora para dar paso a las fuerzas del mercado, el saber experto pone en juego de modo indirecto lo que Rose (1990) llama "el gobierno de las almas". De este modo el dominio experto provee de la distancia fundamental entre los aparatos del estado y el modelamiento de las actividades, deseos, aspiraciones de las sujetos y que bajo una retórica de la libre elección y la autonomía introduce en la experiencia y la vida cotidiana de los sujetos performándola, a través de una serie de "técnicas" mediante las cuales los sujetos se gobernarían a sí mismos, y en el caso de las madres, a sus familias.

\section{Mujeres, cuidados, socialización y disciplina}

Si pensamos en las disciplinas, ya sea como técnicas corporales, de gobierno de la subjetividad o control del discurso, no es difícil percatarse que al interior de las familias éstas técnicas se hallan estrechamente vinculadas con los cuidados maternos. Una primera lectura de la relación entre disciplina y cuidados nos dirige a identificar a la infancia como sujeto privilegiado de disciplinamiento, cuestión que ha sido abordada por una extensa bibliografía, de la cual se destacan los trabajos de Rose (1990; 1998), de Rodríguez Ocaña (1988; 1996; 1999), y de Ruiz y Palacio (1999).

Frente a las preguntas de Rose (1998) de ¿cómo se estableció una especialidad que estudiaba la relación materna?, ¿de qué manera el lenguaje y las evaluaciones de los expertos llegaron a introyectarse en los individuos, en forma de normas de vida, a la vez gratificantes y persecutorias?, la mayor parte de estos trabajos, lo ha hecho desde la perspectiva de la historia de la infancia y la medicalización de la vida infantil, planteando una hipótesis más o menos generalizada de que la familia, sus modos de relación y sus intereses, han quedado unidos a obligaciones sociales que tienen por objeto asegurar la continua reproducción y la crianza de un número adecuado de niños saludables y bien adaptados.

En estos trabajos, la maternidad no constituye el centro de los análisis, sino que es tratada como un tema que emerge, necesariamente, al pretender estudiar y conocer la situación de niñas y niños (García, 2004). Las lecturas feministas (Enhrenreich \& English, 1990; Palacio, 2003) y especialmente la obra de Badinter (1984) trasladaron el foco de atención de los cuidados hacia las madres, bajo el argumento de que a lo largo de la historia la función materna (en cuanto a actitudes, 
comportamientos, prácticas e incluso sentimiento tal como lo plantea Badinter), es menos una expresión de la capacidad biológica o de repertorios "construidos" por las mujeres, que intervenciones ajenas en función de determinados intereses políticos, económicos, ideológicos o religiosos ${ }^{2}$ (Palacio, 1998).

Estos intereses han determinado "en mayor o menor medida, el modo en que las madres han de sentir, actuar y comportarse en relación con la generación y crianza de los hijos" (Palacio, 1998, p. 10). Ello ha dado origen a una serie de mecanismos y estrategias de adoctrinamiento y divulgación dirigidos a transmitir lo que los "expertos" esperan de las mujeres madres.

Para Donzelot (1998) la implementación progresiva de estas estrategias disciplinarias, que conformarán el ya definido complejo tutelar, implicó durante todo el siglo XX, posicionar a las mujeres en una nueva dimensión del espacio doméstico: la encargada del gobierno de las familias. Así, las mujeres, se verán expuestas a un proceso de autonomización que consistirá principalmente en la debilitación de la figura del patriarca. Esta autonomización será la condición de posibilidad de lo social, entendido como un espacio identificado entre las esferas privadas y públicas, es decir una "zona intermedia" y un "un sistema de flotación regulado" (Deleuze en Donzelot, 1998) que articula las familias y al Estado: la familia para subsistir en este entramado público/privado debe por un lado debilitar la figura del padre y por otro, intensificar la figura de la madre, conformando con ello un triángulo entre la madre, el niño y el experto.

La instalación del complejo tutelar como efecto de las nuevas formas disciplinarias de ejercicio del poder, equivale para Donzelot (1998) deslizar la función de la familia de ser objeto de gobierno a un mecanismo por el cual es posible el gobierno, deslizamiento efectuado por una serie de transformaciones ocurridas durante el siglo XIX en adelante en torno a una red de intereses, inquietudes y demandas sobre la familia y la comunidad en general. De esta forma, las disciplinas psi legitimaban las nuevas pretensiones de conocimiento y formas de regulación social que subvierten el orden clásico del gobierno político, basado en la soberanía y el derecho, instituyendo un régimen de poder ejercido a través de mecanismos disciplinarios y de la estipulación de normas para la conducta humana (Porton,2001).

\footnotetext{
2 Esto revela la importancia de puntualizar de qué hablamos cuando afirmamos que las prácticas se "construyen" social y culturalmente, pues en dicha construcción no todas y todos las y los sujetos se sitúan en la misma posición.
}

La familia normal, el niño saludable, la esposa/ madre cuidadora y actualmente, emprendedora, si bien informan sobre ideales culturales que trascienden los límites de los saberes y prácticas $p s i$, son reformulados y legitimados bajo enunciados científicos, es decir verdaderos y objetivos, que incentivan la producción de ciertos modos de relación de las madres con sus familias y no otros. Así podemos apreciar que en los últimos años especialmente, tal como en los programas de intervención psicosociales contemporáneos dirigidos a las mujeres (madres), estos modos son elaborados según toda una terminología de la gestión empresarial y el modelo del capital humano ${ }^{3}$ : nombres de programa tales como "Jefas de Hogar" (SERNAM), "Emprende Mamá" (Chile crece contigo), etc., los cuales rodean los objetivos de intervención en las familias, aportando a la construcción de una noción de sí misma como gestoras y empresarias de los hogares.

Desde esta perspectiva, las relaciones entre la familia y lo social, no son relaciones sintéticas al modo del encuentro de dos espacios constituidos previamente, tal como se expresa en la idea tradicional de la relación entre familia y sociedad; por el contrario, esta relación expresa que lo social no es el afuera de las familias sino más bien el resultado de la nueva posición que adquiere la familia en relación al surgimiento de las disciplinas de las ciencias humanas, por lo que desde su inicio lo social está imbricado con las familias; lo que nos lleva a afirmar que entre lo social y la familia hay una relación inmanente que se sostiene en el ejercicio siempre variante de la disciplina y los saberes disciplinarios.

En ese sentido, la familia comprometerá su flexibilidad para permitir la entrada de los profesionales/ expertos que actuarán menos sobre los sujetos que en la relación entre los sujetos y en los sujetos y su vínculo con las instituciones y con el mercado. En este nuevo contexto, a la familia no le queda otra que gestionar la combinatoria de sus relaciones interpersonales, es decir, lo que para Castell (1984) es "su capital relacional". Para este último autor, sin este nexo intenso y conflictivo de relaciones entre cónyuges, padres, hijas/ os, hermanas/os, etc., la familia corre el riesgo de convertirse en una estructura totalmente porosa y expuesta

\footnotetext{
3 Lo que nos lleva a problematizar los cuidados maternos desde una segunda tecnología de biopoder formulado por Foucault, el dispositivo de seguridad. Para conocer las relaciones que Foucault desarrolla en términos biopolíticos entre disciplina, seguridad y la doctrina del capital humano remitirse a los cursos de College de France de 1978 y 1979 publicados bajo el título de Nacimiento de la Biopolítica y Seguridad, territorio y población, respectivamente.
} 
a todo tipo de agresiones del exterior, mientras que para Donzelot (1998) se trataría de un mecanismo que la hace actuar, cuyo principio es desde siempre "acoplar una intervención exterior a los conflictos o diferencias de potencial en el interior de la familia" (p. 95).

A partir de ello, las mujeres a la vez que deben disciplinar a sus integrantes, introduciendo por múltiples mecanismos la norma y los objetivos del Estado, deberán funcionar de acuerdo a múltiples normas más o menos implícitas y explícitas para los agentes de las ciencias sociales y los/las expertos/as, tal como se muestra en ciertos instrumentos de examen ${ }^{4}$ (protocolos de observación, de entrevista, informes psicosociales) propios del campo psicosocial, en los que se describen los hábitos, costumbres de todo tipo, alimentación, prácticas de higiene y habitabilidad, formas de utilizar el tiempo y el espacio, formas de gestionar los placeres, los afectos y las distancias entre los cuerpos, etc.

Así una evaluación psicosocial de las familias, no es otra cosa que puntuar las normas que la Psicología y los programas de intervención producen en relación a la sostenibilidad de la vida en el orden del uso del tiempo (horarios y tiempos de comida, de trabajo, de recreación, de ocio, etc.), del uso del espacio (distribución espacial de las generaciones y los subsistemas familiares en la casa y las distancias adecuadas entre los cuerpos), los modos de relación entre sus miembros y de manera extraña, la relación entre sus miembros y los profesionales.

Con esto, al evaluar los cuidados parentales, lo que se intenta es evaluar el potencial de la familia para articular de forma no problemática los intereses del Estado, las demandas del mercado y los deseos individuales, es decir, desplegar sus fuerzas sociales. Se trata de modelar y controlar no sólo las prácticas de cuidado sino que también sus significados: el cuidado adquiere un sentido preciso que es la producción de normalidad o de salud y la reducción de los riesgos sociales, a través de prácticas, sentimientos y deseos reguladores que permiten esa "sujeción continua" que la disciplina aporta.

\section{El cuidado en el siglo XX, una cuestión de expertos.}

Una reconstrucción de la historia social del cuidado, nos lleva a la afirmación de que éste ha sido objeto privilegiado del discurso de un importante grupo de disciplinas. La imagen que quiero mostrar ejemplifica

\footnotetext{
${ }^{4}$ El examen para Foucault "es una mirada normalizadora, una vigilancia que permite calificar, clasificar y castigar. Establece sobre los individuos una visibilidad a través de la cual se los diferencia y se los sanciona" (1974, p. 189).
}

no tanto un ideal de la maternidad -que es más o menos constante en Occidente, sino que constituye un ejemplo de los efectos de poder del esquema disciplinario con el cual la Psicología desde sus inicios construyó lo que hoy denominamos el cuidado afectivo.

Si la medicina social y el higienismo fueron los paradigmas hegemónicos de inicios del siglo XX, con los cuales se intentó domesticar los trabajos reproductivos y de cuidados de las madres, bajo el ideal de la "maternidad científica" centrada en la higiene corporal y en el ordenamiento del espacio (Durán, 2009; Palacio, 1998; Rodríguez en Ruiz y Palacio, 1999; Foucault, 1977; Wolf, 2011), la Psicología lo fue durante el período de posguerra y podría decir, que hasta el día de hoy.

Es claro que la segunda posguerra fue el contexto en el cual la Psicología emerge como ciencia tutelar a partir del desarrollo de los estados de bienestar (Rose, 1990), período en que se aprecia asimismo un proceso histórico de aceleradas transformaciones del orden del género y la sexualidad. La caída de los nacimientos, el aumento del divorcio y el aumento del trabajo femenino fueron los tres fenómenos que durante un corto tiempo (los que duró la guerra) tensionaron el orden sexual hegemónico (Cosse, 2008; Tyler, 2011).

Una vez instaurada la paz se aprecia tanto en Estados Unidos como en Europa, un proceso que revertió dichos avances y en el que confluyeron, no sin contradicciones, las políticas estatales, la religión, las regulaciones, las ideas de las élites y el discurso médico/psicológico, hacia una tendencia a la restauración del orden sexual y género prebélico a través de la reafirmación de la organización doméstica nuclear (Cosse, 2008b). De esta forma comenzaba a circular en los discursos sociales -especialmente el de los medios de comunicación y propaganda- lo que Cosse (2008b) denomina el "modelo de familia de la domesticidad" que se trasladó a Latinoamérica con los consecuentes desvíos y resistencia propios de los procesos de recepción de los proyectos pos-coloniales.

A grandes rasgos este modelo:

(...) dibujaba una familia nuclear reducida, basada en una unión heterosexual, legítima e indisoluble, y en la exaltación del amor y la libre elección de la pareja, que demarcó el espacio legítimo de la reproducción y la sexualidad y en la estrecha relación entre padres e hijos, cuyo hogar constituyó un símbolo de la privacidad y la intimidad afectiva y dentro del cual existían diferencias jerárquicas de edad y género. (Cosse, 2008b, p. 65). 
La mujer era confinada al ámbito privado, encargada del hogar y de la crianza de las y los niñas/os y el varón era responsable del sustento económico y de la autoridad dentro de la familia y frente al espacio público.

Se puede afirmar que la fuerza del poder de este modelo se alimentó por: los saberes principalmente psicológicos (desde el conductismo al psicoanálisis), que dieron estatus de objeto de estudio a la relación de la madre con la criatura bajo el problema general de la crianza (Rose, 1998), por las políticas de bienestar de índole familiarista (Bock, 1996) y especialmente en EE.UU, por el desarrollo de la automatización impulsada por la industria militar, que vio en la casa un lugar privilegiado de consumo de un excedente no menor de tecnología militar que no tuvo otro remedio que reciclarse después de finalizada la guerra (Colomina, 2010).

De manera particular, Colomina (2010) estudia la transformación en el diseño, en las técnicas y los materiales de la arquitectura moderna que según su investigación, tomó prestadas -más bien recicló- aquellas desarrolladas por el ejército. La casa de la posguerra, cuyo modelo era la casa Eames, fue construida a partir de componentes pre fabricados pensados originalmente para dar albergue a las tropas, y que ensamblados, hacían de ésta "un sistema ligero de almacenamiento desmontable e infinitamente recombinable que funciona como escenario para una domesticidad sin tregua" (Colombina, 2010, p. 31).

Es un consenso que la casa se ubica en el centro de una serie de transformaciones culturales cuyo objetivo era vivir de manera "moderna" y de acuerdo a las modalidades de la sociedad del consumo (Ávila, 2004; Esguevilla,2009, Ballent, 1996) ; también fue, según la tesis de Colomina (2010), una extensión de la guerra y una nueva dimensión de la guerra fría: los recordados debates de la cocina protagonizados por Nixon y Jrushchov en el año 1959 curiosamente al interior de una cocina en exposición, no harán otra cosa que hacer de la tecnología doméstica un signo de la superioridad de EE.UU.

La automatización del hogar, como uno de los fenómenos más importantes de la posguerra, no consistió simplemente, como podría pensarse, en trasladar tecnología útil a las necesidades del hogar, fue más bien el desarrollo de estas tecnologías las que fueron conformando un tipo particular de hogar, de necesidades y formas de organizar y utilizar el tiempo y el espacio de la casa.

Televisores, lavadoras, insecticidas, microondas, neveras, aire acondicionado, toallas desechables, extractores de aire etc. dieron origen a lo que Colomina señala como una "higienismo tecnológico", una reelaboración del higienismo decimonónico que hacía de las nuevas tecnologías un medio eficiente para combatir las "invisibilidades" que desde las campañas higienistas del siglo anterior fueron incorporadas como amenazas constantes de la población: gérmenes, bacterias y microbios. Amenazas transparentes que circulaban en los hogares blancos de clase media, como espectros incontrolables y que recordaban constantemente, a ese fantasma que recorría Europa y que en el contexto de la guerra fría se trasladaba a los mismos hogares de EEUU como una amenaza permanente del american way of life ${ }^{5}$.

Esta reformulación del higienismo y su vinculación con las tecnologías domésticas/militares fue una de las tantas condiciones de posibilidad del nacimiento del concepto de privacidad contemporáneo: como antítesis del exterior y como lugar de protección. De esta forma la casa se presentaba como un espacio hiperinteriorizado cuya función primaria era filtrar el mundo exterior en metáforas de protección y seguridad derivadas de la amenaza nuclear y la guerra fría y cuyo emblema fue sin dudas el bunker, como una domesticidad llevada a sus límites.

A lo largo del siglo XX, "las imágenes, los modelos prototípicos de casa presentan amas de casa con la ilusión de un mundo bajo su control, lleno de maravillas de las técnicas automáticas, accionadas con mando a distancia, autolimpiables, autocontroladas que ahorraban trabajo" (Colombina, 2010, p. 284).

Lo moderno equivalía a una vida saludable, confortable, urbana y que principalmente incorporaba la técnica, transformando con ello la disposición y las tipologías de vivienda, modificando su conformación, sus usos, y con ellos, las pautas culturales del habitar doméstico. El nuevo símbolo del "vivir mejor", que se transformó en una obsesión masiva de la posguerra, era una mujer mitad humana, mitad electromecánica (Ballent, 1996) ${ }^{6}$ : máquinas ciborg cuyo cuerpo se confundía con los artefactos de una cocina tecnificada.

Al contrario de la hipótesis de Palmarola (2012) según la cual, dentro del ideal de mujer moderna se hacía compatible la paradoja de la liberación tecnológica y la tradición doméstica, la historiografía

\footnotetext{
5 Una propaganda muy similar a la amenaza musulmana después del atentado a las torres gemelas.

6 La serie La Hechizada es el ejemplo del modelo de la madre de la domesticidad en la cultura popular estadounidense y que se exportó a Latinoamérica por casi 50 años, cuyo summum era la rapidez en la puesta en orden de la casa y la aparición y desaparición de todo tipo de objetos.
} 
feminista tienden a afirmar que lo doméstico moderno se hizo posible gracias a los procesos de innovación tecnológica. Para Ehrereich (1990) la "domesticidad moderna" constituyó uno de los tantos efectos del proceso de industrialización. En el momento en que comienza la producción más o menos masiva de ropa y alimentos, emerge la figura de la dueña de casa cuya preocupación será la higiene y el cuidado del hogar y de las/os hijas/os. Anteriormente a la industrialización, las infinitas necesidades que las familias populares y menos acomodadas debían satisfacer con sus propios medios, hacía imposible la preocupación obsesiva por la higiene y menos aún, la preocupación por las relaciones afectivas entre los integrantes de la familia.

Así la domesticidad consistió en resolver la cuestión del trabajo femenino y el lugar de las mujeres en una nueva modalidad de entender la casa; una ocupación y una identidad para ellas dentro de un espacio en donde las actividades "productivas" de corte artesanal realizadas por cada uno de los integrantes de la familia, inclusive los niños y niñas ceden, para proyectar una casa convertida en escaparate o en vitrina de objetos creados masivamente por la nueva producción tecnificada.

Como es de esperar todos estos procesos, provocaron una serie de efectos concretos en la vida de las mujeres: aumento del número de hijos por mujer (el llamado babyboom), la reducción de la edad del casamiento y las tasas de divorcio, la adscripción de las mujeres como responsables exclusivas de las tareas del hogar y finalmente la construcción misma del hogar fordista de la clase media (Prost, 1989).

En este contexto la cuestión del cuidado psicológico adquirió una relevancia inaudita en los estudios sobre el desarrollo infantil, realizados inmediatamente después de la segunda guerra. Tanto en EE.UU como en Inglaterra los trabajos de Ana Freud, John Bolwby, Honrad Lorenz, James Robertson son una muestra más de los muchos estudios que datan de esta época en que se insistirá por múltiples mecanismos discursivos, en la conveniencia y necesidad de la permanencia de las madres junto a sus hijas/os y en la importancia de sus cuidados en el desarrollo conductual y emocional de los infantes.

Con ello se desarrollarán los primeros intentos de formular una teoría general del apego que abarcará tanto el plano de la normalidad y la anormalidad, todos ellos apoyados en datos duros provenientes de observaciones con bebés, del campo de la etología y las ciencias naturales, y que definirán el apego materno como una conducta innata.
La joven ciencia psicológica deviene en una psicología del desarrollo que moviliza sus herramientas conceptuales y de intervención hacia la gestión y control de la separación del niño con su madre. Tanto la "abundancia de apego" como la "falta de apego" serán una preocupación central para el psicólogo de la posguerra, inquieto por controlar los posibles excesos de las mujeres de clase media. ${ }^{7}$

A partir de estas investigaciones, discusiones y teorías se instala lo que para Hays (1998) constituye el modelo de la maternidad intensiva consistente en que el niño o niña “(...) tiene absoluta necesidad de una educación coherente por parte de un único encargado primordial de cuidarlo...y la madre es la mejor persona para ese trabajo" (p. 90) tal como lo entendía Bolwy y los teóricos del apego. Para este modelo los cuidados debían estar centrados en el niño, en sus deseos y necesidades y guiados por los expertos. Se consideraba necesario no sólo atender a sus necesidades materiales sino a sus labores escolares, cada vez más extensas y complejas, sus actividades extracurriculares, su sociabilidad y fundamentalmente, su "mundo interior", otra de las tantas metáforas de protección que relevaban la obsesión por aquella "interioridad" que la domesticidad ofrecía.

La madre debía crear para el infante un entorno que minimizará sus experiencias emocionales negativas, una madre suficientemente buena que le permitiese desarrollarse en concordancia con su identidad y las leyes del crecimiento, consideradas como naturales y universales.

La maternidad intensiva implicaba para las mujeres una gran absorción de tiempo y el desarrollo de una serie de aptitudes destinadas a producir cuidados maternos de calidad que para los expertos consistía en capacidad de respuesta sensible, de alivio de la angustia, de estimulación moderada, calidez, sincronía interaccional e involucramiento (Molina, 2006).

La preocupación instalada en la conciencia de las mujeres performará la hegemonía de la Psicología en

\footnotetext{
En un estudio que en 1948 el Comité de Expertos en Salud Mental de la OMS encarga a John Bolwby y que en 1950 fue publicado con el nombre de "Cuidados Maternos y Salud Mental Infantil", afirma: "casi totalidad de la evidencia de que se dispone se refiere a la relación del niño con la madre, por ser ésta sin duda la que, en circunstancias normales, constituye el más importante nexo del niño durante su primera infancia. Es la madre quien lo alimenta y le limpia, la que le abriga y le presta las atenciones que constituyen sus primeras necesidades de bienestar. Es hacia su madre donde vuelve los ojos cuando siente alguna inquietud o zozobra. Para el niño, el padre representa un papel secundario, cuya importancia crece tan sólo cuando disminuye su sentido del peligro ante la posible privación del afecto materno" (Bowlby, 1982, p.16).
} 
un difuso campo de estudio que hasta ese momento era territorio tanto de la Medicina, del Trabajo social, de la Enfermería, la Pedagogía, como también de la Iglesia y los moralistas: las relaciones familiares y la organización social de los afectos. En este proceso, el Psicoanálisis, bajo la hegemonía de la escuela del yo y la Etología, se convierte en un referente indispensables para la teoría del desarrollo, a través de los cuales el rol de la madre se consagra a la producción de un yo normal entendido como adaptado. Este enfoque recogerá la formulación freudiana contenida en la segunda tópica según el cual el yo es una instancia defensiva (de las agresiones del medio, como las internas,) y dispositivo de adaptación a la "realidad" externa, instituyéndose con ello una sujeta movediza entre las exigencias del estado, de la producción y la moral hegemónica.

Este mecanismo por el cual la disciplina profesional se introdujo de manera ampliada y difusa en la sociedad es lo que Castel (1984) denomina como "el nacimiento de la cultura psicológica" que se inscribió hegemónicamente en el trabajo, a través de la naciente psicología organizacional y en la casa, a través de la Psicología del desarrollo y de la infancia. Para Rose (1990) esta psicologización de la realidad, consistió en un proceso mediante el cual una serie de campos, espacios, problemas, prácticas y actividades (entre los que destaca la crianza y los cuidados) se volvieron una cuestión "psicológica", en el sentido de que se hicieron inteligibles en términos saturados de psicología.

Así mismo, este modo disciplinario con el cual los trabajos y las horas de las mujeres adquirieron visibilidad psicológica, se posicionó como un dispositivo de creación y control de los significados bajo la sintaxis de lo eficiente, lo continuo y productivo, que hacían de los cuidados maternos una experiencia para la madre, de goce y bienestar ${ }^{8}$ y para el infante,

\footnotetext{
Para Bowlby (1982): "De la misma manera, el prodigar los cuidados maternos no puede entenderse en horas de atención diaria sino en términos del goce que ambos obtienen de la convivencia. Ese disfrute y esa estrecha identificación de los sentimientos, sólo son posibles cuando la relación es continua. Hemos venido haciendo singular hincapié en la necesidad de esa continuidad para el buen desarrollo de la personalidad del niño. Pero debemos subrayar que es imprescindible también para el desenvolvimiento de la madre. En la misma medida que el niño necesita sentirse poseído por su madre, necesita ésta percibir que pertenece a su hijo y sólo mediante la satisfacción plena de ese sentimiento le es fácil y hacedero entregarse por completo a su cuidado. Únicamente a la mujer que recibe honda satisfacción al ver cómo va desarrollándose su hijo, desde las diferentes fases de la infancia hasta quedar convertido en un adulto y que sabe fue todo obra de sus cuidados, le es posible prodigarle atenciones constantes noche y día, semana tras semana, años enteros. (p. 81-82)
}

de salud y normalidad, bajo la tutela del saber de los expertos. Un modo disciplinario que tuvo por efectos la restricción de la familia a lo nuclear (en la era nuclear), los cuidados a la intimidad, la articulación de un saber que anticipaba la creciente privatización del bienestar y finalmente, la restricción progresiva de las redes de conocimiento sobre los cuidados que las mujeres creaban en los espacios colectivos, en el que el vínculo familiar dependía menos de los lazos de sangre que del apoyo y el intercambio social.

\section{Conclusiones}

El ejercicio histórico de presentar esta imagen del disciplinamiento del cuidado materno, se inscribe dentro de una preocupación que interroga por la actualidad: las relaciones que la psicología contemporánea establece entre cuidados parentales, salud mental y riesgo social.

Si pensamos en el estatus que tiene el discurso del riesgo social en Latinoamérica, vemos que se ha transformado, desde el fin de las dictaduras, en uno de los discursos sociales con mayor impacto y efectos en las vidas de la población, constituyéndose en palabras de Sepúlveda (2011) en "un campo de saber/poder en torno al cual las nuevas tecnologías de gobierno se van a articular, movilizando para ellos sus respectivos dispositivos de control y regulación" (p. 105). En ese sentido se trata de interrogar/nos cuál es el lugar de las mujeres madres en esta nueva modalidad de control social.

Desde los trabajos de Watson y Bowlby hasta las recientes investigaciones sobre la "sensibilidad parental" dicha relación ha sido incuestionable y por el contrario, se ha encriptado en los últimos años en los imaginarios profesionales como una verdad irrefutable, especialmente a partir de la puesta en marcha de una serie de programas como por ejemplo, Chile crece contigo en el cual el cuerpo de las mujeres se concibe como una extensión del cuerpo de la nación.

Un camino privilegiado para dilucidar los mecanismos precisos de la construcción de esa continuidad, es la misma historia de las mujeres cuya regularidades, bajo múltiples retóricas, nos envían a la idea de las mujeres/madres como garantes del orden social y el desarrollo de la nación, un eterno femenino que transita entre los discurso de la defensa de la nación y la raza a la defensa de la sociedad, de las madres "ignorantes" a las madres con escasa sensibilidad parental, de las madres malcriadoras a las madres devoradoras y con 
ello a las madres esquizogénicas; imágenes que sin duda recogen un imaginario masculino que se resiste a abandonar los privilegios construidos y validados por los relatos científicos que inscriben a los varones blancos heterosexuales y burgueses como los representantes de la cultura, la civilización y el saber y que en el caso de la Psicología debe poner límite a la relación del niño con la madre.

Destaco niño porque las niñas en este imaginario quedaron del lado de la madre, ellas también fueron objeto de una pedagogía del cuidado ya sea para ejercerlos con sus hermanos menores o como futuras madres. Las ideas de las madres chiquitas que Pechin (1999) analiza, fue uno de los efectos más siniestros de lo que constituyó el siglo del niño. Mientras que ellos asistían a la escuela y gozaban de los avances de ese siglo del niño era necesario que ellas, las chiquitas aprendieran lecciones de puericultura y se mantuvieran en sus casas como mano de obra doméstica y de cuidado.

Ahora bien, esta relación (cuidados y problemas psicosociales) también tiene que ver con las posibilidades reales de intervención de la Psicología. Si pensamos que los modelos actuales de intervención, postulan heterogéneos y articulados niveles de análisis (micro/meso/ macro), lo cierto es que los profesionales actúan al nivel de lo micro y lo individual, con escaso participación en las comunidades y nula participación en las decisiones del Estado, de las instituciones y en la economía. En ese sentido, el cuidado se transforma en un campo de intervención privilegiado en la medida en que por un lado, es ahí en donde los profesionales tienen la capacidad para intervenir y por lo tanto, justificar el mercado en expansión de servicios psicológicos y por otro, es el camino más económico para controlar paradójicamente, los procesos de agenciamiento de las familias.

No es fortuito que las dinámicas de las intervenciones apunten a tres objetivos que tal como apreciamos en el ejemplo histórico constituyen objetivos más o menos constantes de disciplinamiento: instalar conductas "correctas" de cuidados, bajo la idea actual del desarrollo de "competencias" parentales, situar estos cuidados en territorios determinados (la casa) y controlar los significados que estos adquieren en las dinámicas familiares y en la vida de las mujeres 9 . De este modo, el cuidado tal como lo construyen las disciplinas, es posible de pensar como un elemento más de la sujeción de los sujetos al espacio y con ello el control de los

\footnotetext{
9 Ninguna mujer se siente con el derecho de pensar el cuidado como fuente de insatisfacción o de cansancio físico y emocional; el significado del cuidado no admite otras interpretaciones más que las hegemónicas.
}

elementos móviles y para el caso de las mujeres, de su adscripción a la casa y a una modalidad de utilizar los tiempos basado en el esquema fordista de producción, utilidad, regularidad y eficiencia.

Con estos antecedentes se tornan absurdos los intentos de pensar los cuidados como una expresión de alguna capacidad biológica de las mujeres. Pero el hecho de que no sea instintivo no quita que las mujeres construyan un saber propio acerca del cuidado y que no necesiten de saberes "expertos". Con esto el problema se desliza del cuidado a las políticas de conocimiento de las disciplinas que conciben el conocimiento científico en la única verdad posible, velando el hecho de que la Psicología y el Psicoanálisis no tienen más de dos siglos de existencia y que las mujeres han cuidado durante toda la historia humana a sus hijas/os sin necesidad de acudir al conocimiento científico de los "expertos".

\section{Referencias}

Avila, E. (2004) Popular Culture in the Age of White Flight: Fear and Fantasy in Suburban Los Angeles. California: University of California Press.

Badinter, E. (1984). ¿Existe el instinto maternal?: historia del amor maternal, siglos XVII al XX. Barcelona: Paidós.

Ballent, A. (1996). La publicidad de los ámbitos de la vida privada. Representaciones de la modernización del hogar en la prensa de los años cuarenta y cincuenta en México. Alteridades, 6(11), 53-74. Recuperado de http://redalyc.uaemex.mx/src/inicio/ArtPdfRed. jsp?iCve $=74711339006$.

Bock, G. (1996). Maternidad y políticas de género: la mujer en los estados de bienestar europeos, 1880-1959. Valencia: Cátedra.

Butler, J. (2006). Deshacer el género. Barcelona: Paidós.

Caruso, M. (2003). "Sus hábitos medio civilizados" enseñanza, disciplinas y disciplinamiento en América Latina. Educación y pedagogía, 15(37), 105-127. Recuperado de http://dialnet.unirioja. es/servlet/articulo?codigo $=2556822$.

Carrasco, C. (2001) La sostenibilidad de la vida humana: ¿un asunto de mujeres? Mientras Tanto, 82, 27-47.

Castell, R. (1984). La gestión de los riesgos: de la antipsiquiatría al post-análisis. Barcelona: Anagrama.

Castell, R. (2003). La inseguridad social: ¿Qué es estar protegido? Buenos Aires: Manantial

Colomina, Beatriz. (2010). La domesticidad en guerra. Madrid: Actar.

Cosse, I. (2008). El modelo conyugal en la ciudad de Buenos Aires de la segunda posguerra: el compañerismo de complementariedad y el impulso familiarista. Trabajos y comunicaciones, 34,63-94. Recuperado de http://dialnet.unirioja.es/servlet/ articulo? codigo $=3863447$.

Cosse, I. (2008b). Familia, sexualidad y género en los años 60. Pensar los cambios desde la Argentina: desafíos y problemas de investigación. Temas y debates, 16, 131-149. Recuperado de http://rephip.unr.edu.ar/bitstream/handle/2133/1547/Familia_sexualidad_y_genero_en_los_a\%C3\%B1 os_60_TyD16-8. pdf?sequence $=1$.

Durán, M. (2009). Medicalización y disciplinamiento. La construcción higienista del espacio femenino, 1850-1920. Nomadias, 9, 
123-139. Recuperado de http://www.revistas.uchile.cl/index.php/ NO/article/viewArticle/12303.

Chambon, A., Irving, A. \& Epstein, L. (Eds.). (2001). Foucault y el trabajo social. Granada: Maristán.

Deleuze, G. (1999). Epílogo. En Donzelot, J. (1999). La policía de las familias (pp. 215-238). Valencia: Pre textos.

Donzelot, J. (1999). La policía de las familias. Valencia: Pre textos.

Esguevilla, D. (2009). Modelos y series en la casa americana de posguerra. (Tesis doctoral). Universidad Politécnica de Madrid. Madrid.

Foucault, M. (1974). Vigilar y castigar. Barcelona: Paidós.

Foucault, M. (1977). Nacimiento de la medicina social. En Estrategias de poder. Madrid: Paidós.

Foucault, M. (2011). El orden del discurso. Barcelona: Tusquet.

Foucault, M. (2006). Seguridad, territorio y población. México: FCE.

Foucault, M. (2011). Nacimiento de la biopolítica. México: FCE.

Enhrenreich, B. \& English, D. (1990). Por su propio bien. 150 años de consejos de expertos a las mujeres. Madrid: Taurus.

Haraway, D. (1995). Ciencia, cyborgs y mujeres. La reinvención de la naturaleza. Madrid, Cátedra.

Hays, S. (1998). Las contradicciones culturales de la maternidad. Barcelona: Paidós.

Macherey, P. (1990). Sobre una historia natural de las normas. En Balbier, E. (1990). Michel Foucault, filósofo. Barcelona: Gedisa.

Molina, M. (2006). Transformaciones Histórico Culturales del Concepto de Maternidad y sus Repercusiones en la Identidad de la Mujer. Psykhe, 15(2), 93-103. Recuperado de http:// www.scielo.cl/scielo.php?script=sci_arttext\&pid=S0718$22282006000200009 \& \operatorname{lng}=e s \& n r m=$ iso $>$. DOI: $10.4067 /$ S071822282006000200009.

Palacio, Irene. (2003). Mujeres ignorantes, madres culpables. Adoctrinamiento y divulgación materno-infantil en la primera mitad del siglo XX. Valencia: Universitat de València.

Palmarola, Hugo. (2012). Conferencia ¿Que hace una chica como Betty Boop en un lugar como este? Recuperado de http://www. odontologia.uchile.cl/agenda/77451/conferenciaque-hace-unachica-como-betty-boop-en-un-lugar-como-este.

Pechin, C. (1999). Infancia, aprendizaje y nacionalidad en los inicios del sistema educativo argentino. En Di Liscia, M. y Salto, G. (Eds.) Higienismo, educación y discurso en la Argentina (1870-1940). Argentina: EdUNLPam .
Porton, N. (2001). Reconfiguración de las prácticas de bienestar infantil: prácticas, riesgo, liberalismo avanzado y gobierno. En Chambon, A., Irving, A. \& Epstein, L. (Eds.) Foucault y el trabajo social (pp. 65-86). Granada: Maristán.

Prost, A. (1989). Fronteras y espacios de lo privado. En Ariés, P. \& Duby, G. (1989) Historia de la vida privada. De la primera guerra mundial a nuestros días (pp.13-154). Madrid: Taurus.

Rodríguez, A. (1999). Apuntes para el análisis de las relaciones entre discurso médico y educación. En Ruiz, C. \& Palacio, I. (1999) Higienismo, educación ambiental y previsión escolar. Valencia: Universitat de València.

Rodríguez Ocaña, E., Ortiz, T. \& García-Duarte, O. (1985). Los consultorios de lactantes y gotas de leche en España. Jano, 29(663-H), 1066-1072.

Rodríguez Ocaña, E. (1988). La constitución de la medicina social como disciplina en España, 1884-1923. Madrid: Ministerio de Sanidad y Consumo.

Rodríguez Ocaña, E. (1996). Una medicina para la infancia. En Borrás, L., José M ${ }^{\mathrm{a}}$ (Dir.). Historia de la infancia en la España contemporánea, 1834-1936, (pp. 149-183). Madrid: Ministerio Trabajo y Asuntos Sociales/Fundación G. Sánchez Ruipérez.

Rodríguez Ocaña, E. (1999). La construcción de la salud infantil. Ciencia, medicina y educación en la transición sanitaria en España. Historia contemporánea, 18, 19-52.

Rose, N. (1990). Governing the soul. The shaping of the private self. London and N. York: Routledge.

Rose, N. (1998). Inventing our selves, psychology, power, and personhood. Cambridge: Cambridge University press.

Ruiz, C. \& Palacio, I. (1999). Higienismo, educación ambiental y previsión escolar. Valencia: Martin editores.

Sepúlveda, Mauricio. (2011). El Riesgo como Dispositivo de Gobierno: Neoprudencialismo y Subjetivación. Psicología, 20(2), 103-124.

Tyler, Elaine. (2011). Cuestiones explosivas: el sexo, las mujeres y la bomba. En Borja-Villel, Manuel (Ed.) Bajo la bomba. El jazz. de la guerra de imágenes trasatlánticas (1946-1956) (pp. 53-85). Barcelona: Macba.

Wolf, Jacqueline. (2001). Don't kill your baby. Public health and the decline of breastfeeding in the 19th and 20th centuries. Columbus: Ohio State University Press. 
